\title{
Are the Knowledge Management Times "A-Changin"”?
}

\author{
John S. Edwards \\ Aston University, Birmingham, UK \\ j.s.edwards@aston.ac.uk \\ DOI: 10.34190/EKM.20.056
}

\begin{abstract}
Knowledge management (KM) is no longer the new kid on the block. The term has been in use for over 30 years, it has been an established field of study for over 25, and this is the $21^{\text {st }}$ ECKM. But how much has KM changed in that time? This paper considers that question by briefly comparing articles dated 1999 in the Web of Science database with those in 2019, and then looking in depth at practical case studies of KM published in 2019 according to that same database. It is common knowledge that the technology available has improved vastly during KM's history, but how has this impacted on other aspects of KM? Major themes from the earliest days of KM, such as repositories and communities of practice, are still highly visible in the literature. The approach taken in this paper is to use a people-processes-technology framework, separate the business processes from the knowledge processes that support them, and examine the linkages between the three elements of the people-processes-technology framework for both types of process. Current research shows processes to be the most studied of the three elements, especially the link whereby people help to design and then operate processes. The technological advances that have had most effect on $\mathrm{KM}$ are in technologies for general application. This is in contrast to the focus of technology research in KM in the 1990s, which had been on specific technologies for KM. Whether the latest technologies for artificial intelligence and analytics are general or specific to KM is a moot point, and probably depends on the background of the person you ask. The weakest current linkages are clearly those in which people should be helping to design the technology in use. Analytics developments in particular are as likely to be inflicted on the users/customers as to be designed by them. Artificial intelligence developments for KM in 2019 do not even include practical case studies, which is worrying.
\end{abstract}

Keywords: case studies; knowledge management history; people; processes; technology

\section{Introduction}

It is generally accepted that Karl Wiig introduced the term knowledge management (KM) for a conference in 1986 organised by the International Labour Organisation of the United Nations, although in fact he called it the management of knowledge (Wiig, 1997). That makes KM more than 30 years old, so it should be a mature discipline by now, but is it? A properly mature discipline would have agreed foundations, or at least established schools of thought based on different foundations (cf. economics). The fact that Wiig coined the term is one of the few things about KM that everyone seems to agree on. There is no widely agreed definition of what KM is, and even attempts to produce one in the academic literature seem to have faded away over the last ten years. The latest international standard for KM systems (e.g. The British Standards Institution, 2018) includes three different definitions of KM, ranging from the anodyne "management with regard to knowledge" to the idealistic "a holistic approach to improving learning and effectiveness through optimization of the use of knowledge, in order to create value for the organization." We do not have space to discuss definitions further here: for the purposes of this paper, an activity is KM if the people writing about it say that it is.

Our objective in this paper is to offer a brief comparison of the state of KM in 2019 with that in 1999, and then carry out a more detailed analysis of the 2019 situation. A particular emphasis will be placed on academic articles that have practical relevance, as the best representation of KM research that is really making a difference to KM practice. This will help academics to see which are currently the most active areas, and where there are gaps.

There is no doubt that KM is still a very active discipline. We chose to use the Web of Science database to look at published articles, as that has been the most consistently curated database over the period from 1999 and is not owned by a single publisher. A search on Web of Science for articles with topic "knowledge management" yielded 1344 papers published in 2019, as compared to a mere 201 that had been published in 1999. The countries most active in publishing KM articles have also changed in that 20-year period (see Figures 1 and 2). In 1999 the USA produced nearly one-third of all articles, followed by England (Web of Science has already broken up the United Kingdom!) and Germany some distance behind. In 2019 the USA remained the largest producer of articles, but only by a small margin from the People's Republic of China, which had been a mere $6^{\text {th }}$ in 1999. The other most notable rises in KM publication activity are those of Brazil (from no publications at all in 1999 to $5^{\text {th }}$ ) and India (from a single publication to $7^{\text {th }}$ ). 


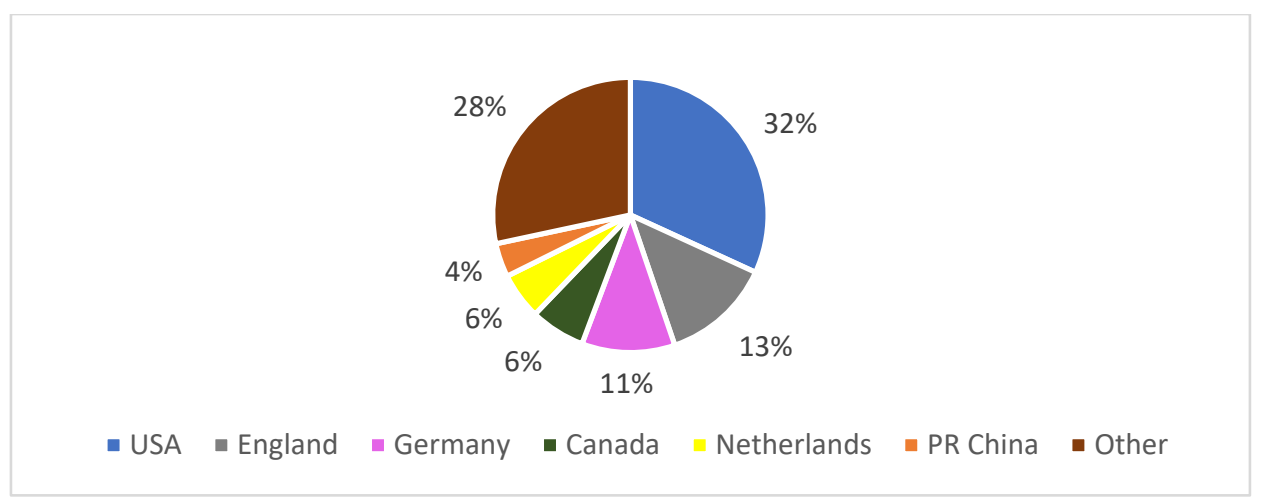

Figure 1: Origin of KM articles published in 1999

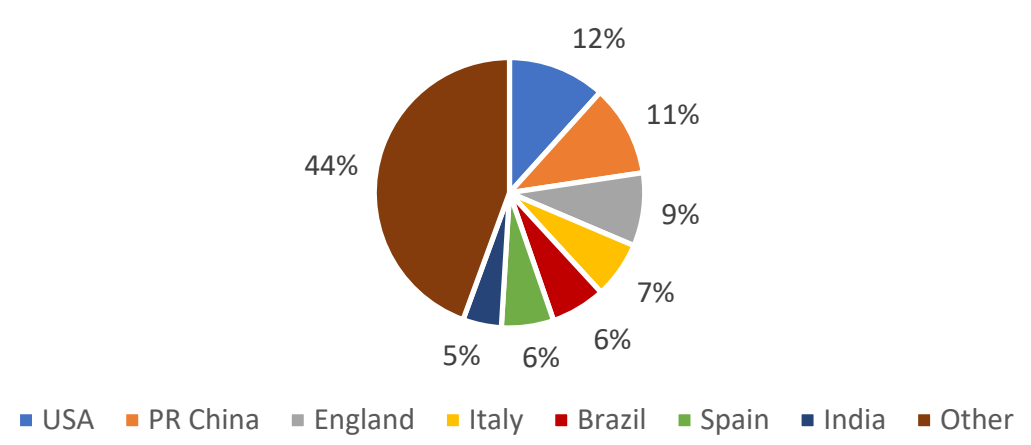

Figure 2: Origin of KM articles published in 2019

Concentrating solely on 2019 articles based on one or more case studies, which may be more indicative of practical KM activity rather than solely academic KM, changes the picture even further. The USA drops to $5^{\text {th }}$, well behind England ( $\left.1^{\text {st }}\right)$, Brazil, Italy and the People's Republic of China. Overall, KM publication activity has spread very widely round the globe (involving 110 different countries in 2019) and is less dominated by the English-speaking countries than 20 years ago.

To give a snapshot of practical and academic KM activity, we will concentrate on these case study articles from 2019 in the rest of the paper. Note that a few of the articles found in the search were early online publication journal articles, so their final published details may eventually show 2020 rather than 2019.

To structure the discussion, one reasonably common conceptual development is to think about KM in terms of the aspects of people, processes and technology (PPT). This was proposed independently by several authors around the beginning of this century, for example by Edwards (2000) and Malhotra (2000), at IBM (Gongla and Rizzuto, 2001), and at Nortel Networks (Massey, Montoya-Weiss and O'Driscoll, 2002). We shall adopt this as the lens through which we look at KM in the rest of this paper.

Section 2 describes the people-processes-technology lens in more detail, then section 3 uses this lens to look at what was published in KM case studies in 2019. Section 4 presents a brief discussion and a little speculation about the future. Section 5 gives the conclusions and the limitations of the study.

\section{The people-processes-technology view of KM}

Figure 3 displays the people-processes-technology view of KM on two levels: the business processes of the organisation concerned, and the knowledge processes that support those business processes, and in turn are influenced by them - for example in learning from experience. 

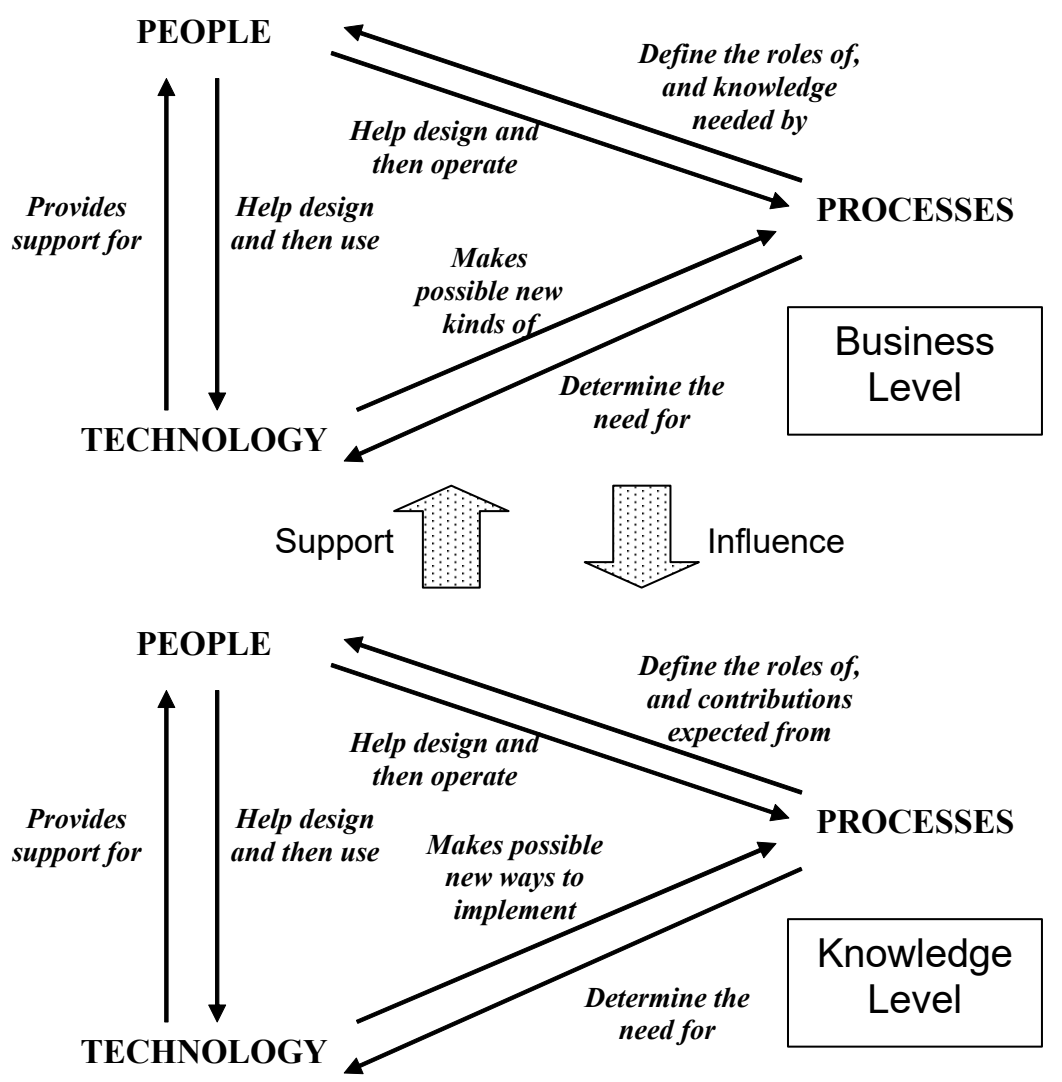

Figure 3: People, processes, and technology interacting at the business and knowledge levels (adapted from Edwards, 2016)

Starting with the three elements, the international standard mentioned in section 1 reflects one significant change in emphasis. It comes under the International Standards Organisation's Technical Committee ISO TC/260 for human resources management, indicating an emphasis on people, whereas in the mid-1990s "boom", KM had a very strong emphasis on technology, partly because of the technology push from many consultancy companies. A more people-centred approach only began to become apparent during the second half of the 1990s. Processes came in last of the three for two reasons, one at each level. Business processes had acquired rather a bad name from the over-hype of the business process re-engineering movement that reached its peak in the early 1990s (Davenport, 1995). At the knowledge level, there has never been complete agreement on a standard set of knowledge processes: Heisig (2009) identified 117 different suggestions in the KM literature. The most common knowledge processes he found were (in descending order of frequency): share knowledge, create knowledge, use knowledge, store knowledge, identify knowledge, acquire knowledge.

Despite these barriers, the broader view involving all three elements began to appear around the turn of the century, as cited in section 1. A key message from this broader view is the need for integration of the three elements people, processes and technology. This means that the links between the elements (as shown in Figure 3) can be as significant for effective KM as the elements themselves.

However, the identification of KM with technology has proved hard to shift. As late as 2003, the majority of organisations still saw KM as a technological issue (Edwards et al, 2003). Even in 2019 there was still a strand of the KM literature concentrating solely on technology, as our analysis in the next section will demonstrate.

\section{Analysis of recent KM case study papers}

\subsection{The search process}

After the initial search for "knowledge management" described in section 1, our expanded search string on Web of Science was: TS="knowledge management" AND (TS=case stud* OR TS=example*). TS represents the "Topic" field, which includes the article title, abstract, author keywords and Web of Science's Keywords Plus ${ }^{\circledR}$ feature, 
while the asterisk * is a wildcard representing any number of characters, including no character. This yielded 324 articles. The search was then refined as follows. First, the abstract (and if necessary the full text) was inspected to establish if the article really described practical case studies, i.e. included one or more organisations in business, the public sector or the third sector. This reduced the number to 202. Next, we skimmed the full text to find articles that described specific KM applications, rather than (say) examining what people in one or more organisations thought about KM in general. This left 124 . Finally, we read the papers in detail to try to identify the focus of the KM study at both the business and knowledge levels, thus giving the full information needed to apply the people-processes-technology framework. This left a sample of 51 case study articles from 2019 for analysis. The refinement process is summarised in Table 1.

Table 1: Stages in refining the 2019 sample

\begin{tabular}{|l|r|}
\hline \multicolumn{1}{|c|}{ Operation } & Number of articles remaining \\
\hline Search for "knowledge management" & 1344 \\
\hline Restriction to “case stud* OR example*” & 324 \\
\hline Elimination of those not actually describing case studies & 202 \\
\hline Elimination of those about KM in general, not a specific application & 124 \\
\hline $\begin{array}{l}\text { Elimination of those lacking sufficient detail on people, processes and } \\
\text { technology }\end{array}$ & 51 \\
\hline
\end{tabular}

\subsection{The sample of case study papers for analysis}

The 51 case study papers from 2019 were spread across 23 application domains. The most common was healthcare (7), followed by manufacturing (6, ranging from handloom weaving to the automotive sector) and software development (4). An analysis of the focus of these papers (at the knowledge level if there is a difference) is shown in Figure 4. Technology no longer dominates as it did in the 1990s, and logically enough the emphasis of research (by definition new work) has shifted to the previously underrepresented processes element. Noteworthy by its absence is artificial intelligence: none of the 20 artificial intelligence papers in the original 1344 includes a practical case study.

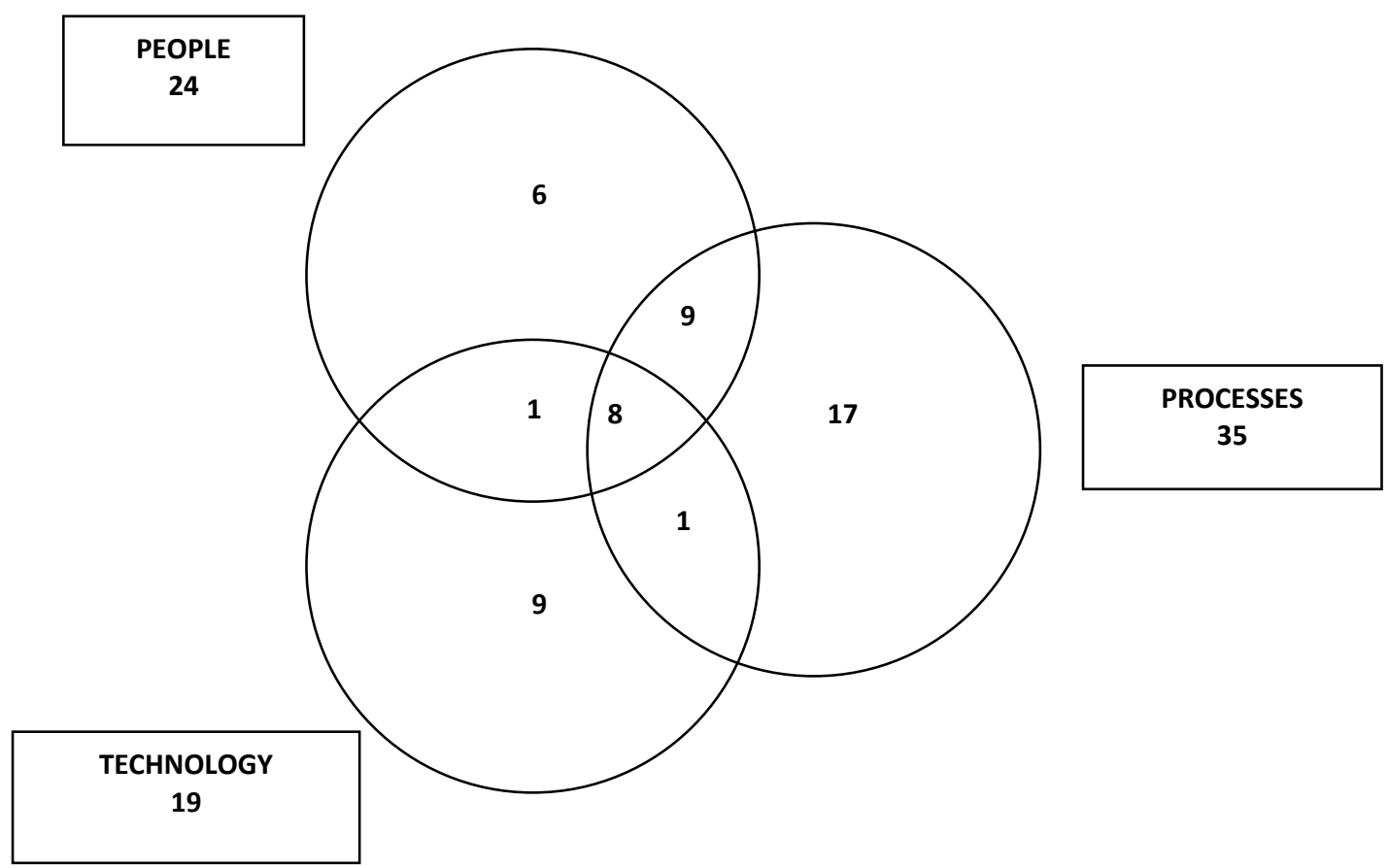

Figure 4: Knowledge level processes in 2019 KM case study papers (source: author)

In view of length restrictions, we cannot discuss all 51 papers here. We will concentrate mainly on those papers that address more than one of the three elements. We start with the "pairs" because it is easier to identify the links in those examples than in papers addressing all three elements. 


\subsection{People and processes}

The majority theme here is an emphasis on the link "people help design and then operate processes" in Figure 3. Andriani et al (2019) examine KM strategies in the fashion industry in Indonesia. They observe that the emphasis needs to shift from tacit to explicit knowledge as the organisation grows. The focus correspondingly shifts from people operating processes themselves, to designing processes for others, with the consequential feedback of "processes defining the roles of people and the knowledge needed by them".

Balijepally and Nerur (2019) present what they say is a rare study of software developers' personal knowledge networks, and how these lead to usable knowledge resources. Not surprisingly, they find differences between experienced developers and new entrants.

Grimsdottir, Edvardsson and Durst (2019) study the knowledge creation processes in three knowledge-intensive SMEs in Iceland; two in software development and the third producing research equipment. They observe that all three rely mainly on semi-formal collaborative processes - typically informally organised (designed "on the fly") but carefully documented. Many techniques are used within these processes, including brainstorming, collaboration meetings, idea days, informal and formal gatherings, mind mapping, internal presentations of solutions, and teamwork and task boards. However, there is no use of specific technology to support them.

Kuniyoshi et al (2019) examine tacit knowledge creation and dissemination in the automotive industry in Brazil, using a process approach based on the much-cited SECI model (Nonaka, 1991). Nearly all of the processes identified were developed by the people concerned, rather than imposed by higher management, and were very similar between the two cases studied. Latilla et al (2019) analyse a similar topic (they call it knowledge transfer) in a very different type of organisation - five firms from the arts and crafts sector in Italy. Here they find the firms each have very different processes, while senior management has little appreciation of the knowledge of the craftspeople and its transfer.

Woydack (2019) examines a multilingual call centre in London. Her focus is on the value of the scripts used. She finds that although they by definition embody the call centre's processes, they do not entirely determine them, and that it is essential for call centre agents to improvise around the scripts in order to succeed. The emphasis here is thus "people operating the processes". Their immediate managers are aware of this improvisation, but corporate management are completely unaware of it. So much so that corporate management state that recruitment is solely on the basis of language fluency, whereas the call centre managers who actually recruit the staff do not stick to this: processes leading to a very significant difference in role requirements.

Ahmad and Barner-Rasmussen (2019) study a less constrained linguistic issue: the use of various languages in a multilingual Finnish company. They find that employees switch between languages in a purposeful way to support different aspects of knowledge sharing. For example, technical discussions have to stay in English (the language used in the company documentation) but enhancing inclusion in knowledge sharing activities typically prompts the use of another language. Again we see people operating the knowledge sharing processes "on the fly".

The two other papers under this heading focus on the complementary link: "processes define the roles and contributions expected from people". One is by Pauluzzo and Cagnina (2019), who investigate an international joint venture based in India, especially how trust supports KM processes. A key finding is that trust alone is not enough, and specific facilitation roles and knowledge acquisition skills also need to be added. The other is from Smuttrasen and Heo (available online 2019), who also look at cross-border KM, in this case in four international companies in Thailand. Their conclusions similarly focus on the roles that are needed, especially leadership roles. They do however find that "the managers in this study have not effectively fulfilled most of these roles".

\subsection{Processes and technology}

The one paper with this focus is by Saeed et al (2019), They investigate how knowledge is shared over time when there are substantial changes in the actors involved, using the example of organizing international conferences. There is often virtually no overlap between the committee members from one such event to the next: Saeed et al (2019) label this nomadic knowledge, noting that the urgency of the tasks at hand often pushes out knowledge sharing. Only once this type of knowledge has been identified can the link "processes determine the need for technology" in Figure 3 come into play as it should. However, there also needs to be the feedback from 
technology into the process. Familiar KM software such as repositories or online communities of practice can be useful, but only if integrated into the new committee's operations properly.

\subsection{Technology and people}

There is also just one paper with this focus (Awazu, Mariano and Newell, 2019). The authors examine projectbased work in a global technology company, concentrating on its lead tracking system, and explain how people affect technology use by adopting different roles. This is the "people help design and then use technology" link in Figure 3. A particular point of interest is that the issues generally referred not to the technology itself, but associated documentation and other aspects - the functional requirements document, a PowerPoint presentation on gap analysis, and how to use an email account on behalf of someone else.

\subsection{People, processes and technology}

Blake et al (2019) investigate the vital topic of knowledge sharing in the transport sector in New Zealand during recovery from a major earthquake. Cross-boundary knowledge and information flows between different organisations turned out to be crucial. Successful enablers included the collection of novel data ("people help design and then operate [new] processes"), using existing sources in novel ways ("technology makes possible new kinds of process" that are then designed by the people involved), and deploying social capital to help the information flow ("people help operate processes").

Yang et al (2020) look at the effectiveness of the lessons learned system intended to support storage and sharing of knowledge between projects in Siemens. They conclude that the people and processes elements are more important to the success of the system than the technology. They offer recommendations under each of the three elements: a culture encouraging both formal and informal knowledge sharing; an information communication system that is more social media-like; and building the use of the system into the project management processes.

It is quite common for the assessment of maturity in a KM maturity model to be based on people, process and technology elements (e.g. Hsieh, Lin and Lin, 2009). Gemke et al (available online 2019) examine how two Dutch police forces have implemented intelligence-led policing, which necessarily has consequences for KM. They present a KM maturity model including people, technology structure and culture, and use processes as the basis of most of their analysis and discussion. Jorgensen et al (2019) use the five-stage maturity model for communities of practice proposed by Gongla and Rizzuto (2001) to understand communities of practice. Their case concerns a global engineering company specialising in the pharmaceutical sector and headquartered in Denmark. Enablers at each of the stages of maturity are considered under the headings people behaviour, process support and enabling technology (though no CoP in the case company has yet reached the fifth stage). People elements emerge as the most important enablers, followed by processes and then technology. Note that there are also two maturity model papers in the processes-only category (Batista et al, 2019, Pauli and Sell, 2019).

Haamann and Basten (2019) specifically examine the role of information technology in knowledge processes in software development, especially knowledge use/application, and deduce the importance of people and process elements. It is noteworthy that PPT is still regarded as novel enough to warrant publication in a specialised KM journal. Muttis and Fidalgo (2019) analyse the use of a best practice database (a repository) in Barcelona City Council, and also find that the effective use of technology requires changes in people and processes, particularly what they describe as knowledge ownership. Stenholm, Catic and Bergsjo (2019) find similar limitations with the use at an automotive manufacturing site in Sweden of an Engineering Checksheet (more sophisticated than the name implies, a spreadsheet acting as index to a document repository).

Wang and Wang (available online 2019) compile five cases of KM in cybersecurity in US business organisations. They take a process-based approach, indeed viewing KM itself as a process, within which the importance of people ("processes defining contributions expected from people") and technology ("processes determine the need for technology") are established.

\subsection{People}

Case papers focusing on people generally concentrate on finding out the views of people in one or a few organisations about knowledge sharing approaches. The sectors concerned vary from healthcare - both administration (Akhnif, Macq and Meessen, 2019) and clinical decision-making (Mazenyte and Petraite, 2020) - 
through international development (Tounkara, 2019) to electronics manufacturing (Hsieh, Chen and Liu, 2019). One fascinating finding is from Butt and Ahmad (2019), who offer evidence of managers in 4 firms in the UAE admitting that they hide knowledge from their superiors.

\subsection{Processes}

Most papers under this heading examine the processes concerned in knowledge sharing and/or learning. Vasconcelos et al (2019) study how these are affected by the strategic balance between knowledge exploitation and knowledge exploration.

Poleza, Davila and Ribeiro (2020), using a healthcare example from Brazil, demonstrate that CommonKADS, a methodology for developing knowledge-based systems with its roots in the 1980s (e.g. Schreiber et al, 1994), still has a role to play in understanding the knowledge creation process.

Sharing tacit knowledge remains an active research topic, especially the nuanced and controversial issue of the extent to which tacit knowledge can be made explicit. Wei, Atalag and Day (2019) describe a system in the healthcare domain based on making tacit knowledge explicit, yet acknowledge that "[Tacit] Knowledge sharing is complex and ambiguous" (p.224).

Preserving knowledge between projects in project-based organisations is also an active theme (e.g. Paton and Andrew, 2019).

\subsection{Technology}

Most papers focusing solely on technology appear in engineering or information technology journals. Occasionally this focus is understandable, as when Zanuzzo et al (2019) study which tools are used for knowledge sharing in a public institution in Brazil, not having the scope to include process or people elements. They find the most commonly used are institutional e-mail, the holding of online meetings, the provision of documents on institutional platforms, and the use of an instant messaging application.

However, work that remains solely focused on technology, yet would surely benefit from taking a more integrated view, still features in the literature. For example, Orenga-Rogla and Chalmeta (2019) propose a methodology for the use of Web 2.0 and Big Data tools to improve KM processes by developing better KM systems (they term these KMS 2.0 even though others have used similar terms before). They carry out a "proof of concept" test on the knowledge processes relating to business intelligence in an oil and gas company, but tellingly the researchers and the company staff responsible for business intelligence propose the business processes for which this would be useful without actually consulting the people who operate them or manage them. This is a recipe for KM system failure, as has been known for many years (e.g. Edwards and Kidd, 2003).

\section{Discussion}

The practical KM case studies from 2019 show a healthy balance between emphasis on people, process and technology elements. Eight of the 51 papers cover all three elements equally, and indeed three of those (Haamann and Basten, 2019, Jorgensen et al, 2019, Muttis and Fidalgo, 2019) explicitly adopt a peopleprocesses-technology framework.

The relative novelty of the process element in research helps explain why more than two-thirds of the 2019 papers address it. The major themes are knowledge sharing processes - this is consistent with knowledge sharing being the most researched topic within KM (see e.g. Ribière and Walter, 2013) - and the link "people helping to design and then operate processes" in Figure 3.

Those two themes are also the principal ones found under the people element, showing a refreshing degree of integration. This is in contrast to some of the technology-focused work, as we now explain.

Technological support specific to KM has hardly changed in 20 years, since the development of repositories and online Communities of Practice. Both of these are still evident in the sample (e.g. Abdellatif, Capretz and Ho, 2019, Jorgensen et al, 2019). Most support comes from technologies for general use, and so the biggest change has come from the developments in social media (e.g. He et al, 2019). The latest developments in artificial intelligence, such as deep learning, have had surprisingly little impact. Even the 2019 artificial intelligence papers that do not qualify as practical case studies rely on well-tried techniques such as case-based reasoning. This is 
one indicator of an apparent gap in the development of technology support for KM. Most new technological developments appear in engineering or information technology journals. However, what counts as implementation or a proof of concept in such journals often only requires having a system that functions in the research setting: business, management and specialised KM journals have rather more stringent requirements in order to regard an application as implemented in practice. This difference contributes to "people design and then use technology" being the weakest link of those in Figure 3.

Moving away from our particular lens, specific themes that emerge from the analysis include the importance of semi-formal or informal KM processes, the development and use of maturity models for KM, and the issues that apply to KM in project-based organisations.

There seems to be no observable geographical, sector or organisational bias in the reported applications of KM. The set of 51 papers includes cases from all inhabited continents: North America, South America, Europe, Asia, Africa and Oceania. Sectors range from arts and crafts and handloom weaving, through healthcare to leadingedge technology; organisations range from global multinationals to SMEs.

The most important academic implications from the analysis are the need to take a holistic approach to KM, including people, processes and technology - and especially not to examine the technology in isolation. The most important managerial implications are first, to focus on what increasing seems to be the key link, people helping to design and then operate processes, and second, not to let innovative technology drive KM projects, but rather for the KM needs to drive the project using technology that is already there, whether new or not-sonew.

\section{Conclusion}

The knowledge management literature is gradually changing, offering a much more balanced view of people, processes and technology elements than it did in the $20^{\text {th }}$ century. The link "people helping to design and then operate processes" features particularly strongly. On the other hand, the link "people design and then use technology" is clearly the weakest. It seems reasonable to propose that the technology development work would benefit from more of a PPT emphasis than one on technology alone. The integrating nature of processes in the PPT framework gives the expectation that processes will - as they should - continue to occupy a key position in future KM research.

The principal limitations of this study are that it is based solely on academic publications listed in one database (Web of Science) as dated 2019, and that the analysis is restricted to those papers which included sufficient information on people, process and technology elements. Future studies could cover additional databases and/or a longer time period, and also contact the authors of papers describing specific practical KM case study applications to obtain the missing detail on people, process and technology where necessary.

\section{References}

Abdellatif, T.M., Capretz, L.F. and Ho, D. (2019) “Automatic recall of software lessons learned for software project managers," Information and Software Technology, Vol 115, pp 44-57.

Ahmad, F. and Barner-Rasmussen, W. (2019) "False foe? When and how code switching practices can support knowledge sharing in multinational corporations," Journal of International Management, Vol 25, No. 3

Akhnif, E., Macq, J. and Meessen, B. (2019) "The place of learning in a universal health coverage health policy process: the case of the RAMED policy in Morocco," Health Research Policy and Systems, Vol 17

Andriani, M., Samadhi, T., Siswanto, J. and Suryadi, K. (2019) "Knowledge management strategy: an organisational development approach," Business Process Management Journal, Vol 25, No. 7, pp 1474-1490.

Awazu, Y., Mariano, S. and Newell, S. (2019) "The mediating role of artifacts in position practice at work: Examples from a project-based context," Information \& Management, Vol 56, No. 4, pp 602-613.

Balijepally, V. and Nerur, S. (2019) "Social Capital and Knowledge Networks of Software Developers: A Case Study," Journal of Database Management, Vol 30, No. 4, pp 41-80.

Batista, L., Dora, M., Toth, J. et al. (2019) "Knowledge management for food supply chain synergies - a maturity level analysis of SME companies," Production Planning \& Control, Vol 30, No. 10-12, pp 995-1004.

Blake, D.M., Stevenson, J., Wotherspoon, L., Ivory, V. and Trotter, M. (2019) "The role of data and information exchanges in transport system disaster recovery: A New Zealand case study," International Journal of Disaster Risk Reduction, Vol 39

Butt, A.S. and Ahmad, A.B. (2019) "Are there any antecedents of top-down knowledge hiding in firms? Evidence from the United Arab Emirates," Journal of Knowledge Management, Vol 23, No. 8, pp 1605-1627.

Davenport, T.H. (1995) “The Fad That Forgot People," Fast Company, No. 1, pp 70-74. 
Edwards, J.S. (2000) "Artificial Intelligence and Knowledge Management: How Much Difference Can It Really Make?," in Proceedings of KMAC2000. Knowledge Management Beyond The Hype: Looking Towards The New Millennium, Aston University, Birmingham, UK, pp 136-147.

Edwards, J.S., Handzic, M., Carlsson, S. and Nissen, M. (2003) "Knowledge Management Research \& Practice: Visions and Directions," Knowledge Management Research \& Practice, Vol 1, No. 1, pp 49-60.

Edwards, J.S. and Kidd, J.B. (2003) "Knowledge Management sans frontières," Journal of the Operational Research Society, Vol 54, No. 2, pp 130-139.

Edwards, J.S., (2016), "Processes: Still the poor relation in the knowledge management family?," Successes and Failures of Knowledge Management, Liebowitz, J., ed., pp 59-69, Morgan Kaufmann/Elsevier, San Francisco, CA.

Gemke, P., Den Hengst, M., Van Rosmalen, F. and De Boer, A. (available online 2019) "Towards a maturity model for intelligence-led policing A case study research on the investigation of drugs crime and on football and safety in the Dutch police," Police Practice and Research

Gongla, P. and Rizzuto, C.R. (2001) “Evolving communities of practice: IBM Global," IBM Systems Journal, Vol 40, pp 842862.

Grimsdottir, E., Edvardsson, I.R. and Durst, S. (2019) “Knowledge creation in knowledge-intensive small and medium sized enterprises," International Journal of Knowledge-Based Development, Vol 10, No. 1, pp 75-94.

Haamann, T. and Basten, D. (2019) "The role of information technology in bridging the knowing-doing gap: an exploratory case study on knowledge application," Journal of Knowledge Management, Vol 23, No. 4, pp 705-741.

He, W., Zhang, W.D., Tian, X., Tao, R. and Akula, V. (2019) “Identifying customer knowledge on social media through data analytics," Journal of Enterprise Information Management, Vol 32, No. 1, pp 152-169.

Heisig, P. (2009) “Harmonisation of knowledge management," Journal of Knowledge Management, Vol 13, No. 4, pp 4-31.

Hsieh, P.J., Lin, B. and Lin, C. (2009) "The construction and application of knowledge navigator model (KNMTM): an evaluation of knowledge management maturity," Expert Systems with Applications, Vol 36, No. 2, pp 4087-4100.

Hsieh, P.J., Chen, C.C. and Liu, W. (2019) "Integrating talent cultivation tools to enact a knowledge-oriented culture and achieve organizational talent cultivation strategies," Knowledge Management Research \& Practice, Vol 17, No. 1, pp 108-124.

Jorgensen, R., Scarso, E., Kirchner, K. and Edwards, K. (2019) “Exploring the maturity and development of global communities of practice," Knowledge and Process Management, Vol 26, No. 4, pp 321-331.

Kuniyoshi, M.S., Gava, R.D.V., Gaspar, M.A. and Ruggieri, R. (2019) “Tacit Knowledge management in product development: case studies on companies it the automotive industry," Navus-Revista De Gestao E Tecnologia, Vol 9, No. $1, \mathrm{pp} 37-48$.

Latilla, V.M., Frattini, F., Petruzzelli, A.M. and Berner, M. (2019) "Knowledge management and knowledge transfer in arts and crafts organizations: evidence from an exploratory multiple case-study analysis," Journal of Knowledge Management, Vol 23, No. 7, pp 1335-1354.

Malhotra, Y., (2000), "From information management to knowledge management: Beyond the 'Hi-tech hidebound' systems," Knowledge Management for the Information Professional, Srikantaiah, K. and Koenig, M.E.D., eds., pp 37-61, Information Today Inc, Medford, NJ.

Massey, A.P., Montoya-Weiss, M.M. and O'Driscoll, T.M. (2002) “Knowledge management in pursuit of performance: Insights from Nortel Networks," MIS Quarterly, Vol 26, No. 3, pp 269-289.

Mazenyte, B. and Petraite, M. (2020) "Mediating knowledge across health ecosystems: a qualitative field study," Measuring Business Excellence, Vol 24, No. 1, pp 52-68.

Muttis, N.B. and Fidalgo, Y.F. (2019) "How Relevant Are the Best Practice Projects as Strategy for Knowledge Management? Case Study of Best Practice on Social Rights Database of Barcelona City Council," Revista Del Clad Reforma Y Democracia, No. 74, pp 95-+.

Nonaka, I. (1991) "The Knowledge Creating Company," Harvard Business Review, Vol 69, No. 6, pp 96-104.

Orenga-Rogla, S. and Chalmeta, R. (2019) "Methodology for the Implementation of Knowledge Management Systems 2.0: A Case Study in an Oil and Gas Company," Business \& Information Systems Engineering, Vol 61, No. 2, pp 195-213.

Paton, S. and Andrew, B. (2019) "The role of the Project Management Office (PMO) in product lifecycle management: A case study in the defence industry," International Journal of Production Economics, Vol 208, pp 43-52.

Pauli, C. and Sell, D. (2019) "Knowledge management in project management offices: diagnosis and definition of strategies for a private research institute," Revista De Gestao E Projetos, Vol 10, No. 3, pp 47-63.

Pauluzzo, R. and Cagnina, M.R. (2019) "A passage to India: cultural distance issues in IJVs' knowledge management," Knowledge Management Research \& Practice, Vol 17, No. 2, pp 192-202.

Poleza, M., Davila, G.A. and Ribeiro, D.I. (2020) "Knowledge Management in Health Care: knowledge assets mapping with CommonKADS," Navus-Revista De Gestao E Tecnologia, Vol 10

Ribière, V. and Walter, C. (2013) "10 years of KM theory and practices," Knowledge Management Research \& Practice, Vol 11, No. 1, pp 4-9.

Saeed, S., Pipek, V., Rohde, M. et al. (2019) “Nomadic Knowledge Sharing Practices and Challenges: Findings From a LongTerm Case Study," leee Access, Vol 7, pp 63564-63577.

Schreiber, A.T., Wielinga, B.J., Akkermans, J.M., van de Velde, W. and de Hoog, R. (1994) "CommonKADS: a comprehensive methodology for KBS development," IEEE Expert, Vol 9, pp 28-37. 
Smuttrasen, K. and Heo, D. (available online 2019) "The impact of leader roles on cross-border knowledge management and the development of boundaryless business models: A case study of Thai construction companies," Knowledge and Process Management

Stenholm, D., Catic, A. and Bergsjo, D. (2019) "Knowledge reuse in industrial practice: evaluation from implementing engineering checksheets in industry," Design Science, Vol 5

The British Standards Institution (2018) BS ISO 30401:2018 Knowledge management systems - Requirements, BSI Standards Limited, London.

Tounkara, T. (2019) "A framework to analyze knowledge management system adoption through the lens of organizational culture," Ai Edam-Artificial Intelligence for Engineering Design Analysis and Manufacturing, Vol 33, No. 2, pp 226-237.

Vasconcelos, A.C., Martins, J.T., Ellis, D. and Fontainha, E. (2019) "Absorptive capacity: A process and structure approach," Journal of Information Science, Vol 45, No. 1, pp 68-83.

Wang, S.H. and Wang, H. (available online 2019) "Knowledge Management for Cybersecurity in Business Organizations: A Case Study," Journal of Computer Information Systems

Wei, P.C., Atalag, K. and Day, K. (2019) "An openEHR Approach to Detailed Clinical Model Development: Tobacco Smoking Summary Archetype as a Case Study," Applied Clinical Informatics, Vol 10, No. 2, pp 219-228.

Wiig, K. (1997) “Knowledge management: where did it come from and where will it go?," Expert Systems with Applications, Vol 13, No. 1, pp 1-14.

Woydack, J. (2019) "Language management and language work in a multilingual call center: An ethnographic case study," Revista Internacional De Organizaciones, No. 23, pp 79-105.

Yang, Y., Brosch, G., Yang, B. and Cadden, T. (2020) "Dissemination and communication of lessons learned for a projectbased business with the application of information technology: a case study with Siemens," Production Planning \& Control, Vol 31, No. 4, pp 273-286.

Zanuzzo, L.T., Besen, J., Santos, F.B., Mussi, C.C. and de Lima, M.A. (2019) "Knowledge sharing: case study of the Institut Federal de Santa Catarina," Navus-Revista De Gestao E Tecnologia, Vol 9, No. 4, pp 177-194. 